doi: $10.2306 /$ scienceasia1513-1874.2014.40.379

\title{
Protocorm-like body proliferation of Grammatophyllum speciosum through asymbiotic seed germination
}

\author{
Sainiya Samala ${ }^{\mathrm{a}, *}$, Sompong Te-chato ${ }^{\mathrm{b}}$, Sureerat Yenchon ${ }^{\mathrm{b}}$, Kanchit Thammasiri $^{\mathrm{c}}$ \\ a Biology Program, Faculty of Science and Technology, Suratthani Rajabhat University, \\ Suratthani 84100 Thailand \\ b Department of Plant Science, Faculty of Natural Resources, Prince of Songkla University, Hat Yai, \\ Songkhla 90112 Thailand \\ c Department of Plant Science, Faculty of Science, Mahidol University, Rama 6 Road, \\ Bangkok 10400 Thailand
}

*Corresponding author, e-mail: saineeya@hotmail.com

Received 8 Dec 2013

Accepted 16 Nov 2014

\begin{abstract}
Viability of Grammatophyllum speciosum seeds was evaluated by a TTC (2,3,5-triphenyl tetrazolium chloride) test. The seeds were then asymbiotically germinated on different agar media under aseptic conditions. The results showed that keeping the seeds in the dark at $30^{\circ} \mathrm{C}$ for 1 day gave $99 \%$ of red staining embryos (referred to as viable). After sowing the seeds on half-strength Gamborg's B5 medium supplemented with $0.1 \%$ activated charcoal (AC) for 30 days, germination of those seeds was observed. Half-strength MS medium (1/2 MS) supplemented with $1 \mathrm{mg} / \mathrm{l} \mathrm{6-}$ benzylaminopurine in combination with $0.5 \mathrm{mg} / \mathrm{l} \alpha$-naphthalene acetic acid, $15 \%$ coconut water, $0.2 \%$ AC, and $0.7 \%$ agar gave the highest percentage of protocorm-like body (PLB) induction and proliferation. The PLBs could be regenerated into complete plantlets with vigorous shoot and root formation on $1 / 2 \mathrm{MS}$ medium without any plant growth regulators. The survival rate of plantlets was $70 \%$ after hardening off in the greenhouse for 1 month.
\end{abstract}

KEYWORDS: in vitro, tiger orchid, micropropagation

\section{INTRODUCTION}

The Orchidaceae, a highly evolved, diverse, and successful families of flowering plants, constitutes about $40 \%$ of the monocotyledonous taxa. There is a great demand for potted orchids and cut flowers in international as well as domestic markets ${ }^{1}$. Orchidaceae is the largest and the most specialized family of flowering plants. All the species in this family are listed in the endangered species of wild fauna and flora in Appendix II of the Convention of International Trade $^{2}$.

Grammatophyllum speciosum Blume or tiger orchid is a beautiful endangered species which is also the largest orchid plant in the world, in addition to the largest epiphytes in general. Conservation effort has been challenged to propagate and reintroduce species that have special horticultural or educational value ${ }^{3}$.

Tissue culture technique was firstly introduced and applied to Cymbidium orchids by $\mathrm{Morel}^{4}$. By this technique, culture methods, culture media, and various explants for orchid tissue culture were introduced and developed by several workers. Shoot tips are the most frequently used for orchid tissue culture. However, protocorms derived from germinating seeds and protocorm-like bodies (PLBs) are also applied ${ }^{5-7}$. Culture medium, namely Vacin and Went (VW) ${ }^{8}$ and Murashige and Skoog (MS) ${ }^{9}$, are usually employed for in vitro orchid culture ${ }^{5,10,11}$. Half strength MS medium is also used successfully for orchid culture ${ }^{12}$.

In $G$. speciosum, the first report on an in vitro establishment for micropropagation has been described by Sopalun ${ }^{13}$. In this report, PLBs were induced from shoot tips. The explants were incubated in $1 / 2 \mathrm{MS}$ liquid medium containing $2 \%$ (w/v) sucrose without any plant growth regulators (PGRs). In this study, effort has been made to develop a protocol for the in vitro propagation or conservation of G. speciosum. The goal of this study was to establish an effective propagation system for the large-scale propagation to meet commercial needs and to re-establish this threatened orchid species back into the original habitats. 


\section{MATERIALS AND METHODS}

\section{Plant materials}

The capsules or pods of G. speciosum orchid were collected from plants with self-pollination for 150 days after pollination (DAP). The capsules were harvested in March 2012 at Suratthani province. The capsules were brought to the laboratory for disinfection and culture.

\section{Seed morphology and viability studies}

For seed viability analysis, freshly isolated seeds from capsules were stained with $1 \%(\mathrm{v} / \mathrm{v}) 2$, 3, 5-triphenyl tetrazolium chloride (TTC) in darkness overnight under shaking condition at $5 \mathrm{rpm}$ for $30 \mathrm{~min}$ and kept under static condition at $30^{\circ} \mathrm{C}$ for $24 \mathrm{~h}$. The seeds were then observed under a stereomicroscope. Percentage of seed viability was calculated by the number of red colour staining embryos divided by the total number of seeds examined and multiplied by 100 .

\section{Effects of basal media on seed germination}

To determine the effects of basal media on seed germination and subsequent development to protocorms, capsules at 150 DAP were used as seed explants. The capsules were disinfected and cut vertically over a sterile Petri-dish. The seeds were then removed and placed on the filter paper. The seeds were surface sterilized again by dipping into $15 \%(\mathrm{v} / \mathrm{v})$ sodium hypochlorite $(\mathrm{NaOCl})$ solution containing $0.5 \%(\mathrm{v} / \mathrm{v})$ Tween-20 for $10 \mathrm{~min}$, rinsed three times with sterile distilled water, and placed on half strength Gamborg's B-5 ( $1 / 2$ B5) or New Dogashima (ND) or half strength Murashige and Skoog (1/2 MS) medium supplemented with $0.1 \%$ activated charcoal (AC) and kept at $25 \pm 1{ }^{\circ} \mathrm{C}$ with a $16 / 8 \mathrm{~h}$ photoperiod. All experiments were performed in three independent replicates with 10 culture Petri dishes per replication. In each Petri dish, one gram of seeds (approximately 815 seeds) was used. The germination percentage of seeds at 30 days was calculated by the number of germinated seeds or protocorms divided by the number of seeds cultured and multiplied by 100 . The seedderived protocorms were used in these experiments related to PLB induction and proliferation.

\section{PLB induction, proliferation, and plantlet regeneration}

For PLB induction, seed-derived protocorms at 3 months of culture (approximately $5 \mathrm{~mm}$ in length) from previous step were transferred to $1 / 2 \mathrm{MS}$ medium supplemented with $1 \mathrm{mg} / \mathrm{l}$ of 6-benzylaminopurine
(BA) alone or in combination with $0.5 \mathrm{mg} / \mathrm{l}$ of $\alpha$ naphthalene acetic acid (NAA), with or without $0.2 \%$ $\mathrm{AC}, 15 \%$ coconut water $(\mathrm{CW})$ and $0.7 \%$ agar. Ten explants were put in each culture bottle and six culture bottles were used for each treatment. The percentage of PLB formation and the number of PLBs per explant were recorded after 8 weeks of culture. The proliferation rate was also calculated after 10 weeks of culture.

For plantlets developed from PLBs, the cluster of PLBs (3-5 PLBs) were cultured on 1/2 MS medium without any plant growth regulators or supplemented with $1 \mathrm{mg} / \mathrm{l} \mathrm{BA}$ in combination with $0.5 \mathrm{mg} / \mathrm{l}$ NAA, $15 \% \mathrm{CW}, 0.2 \% \mathrm{AC}$, and $0.7 \%$ agar. The number of shoots was recorded after 3 months of culture.

All cultures were maintained at $25 \pm 2{ }^{\circ} \mathrm{C}$ under a $16 \mathrm{~h}$ photoperiod with light at an intensity of $10 \mu \mathrm{mol}$ $\mathrm{m}^{-2} \mathrm{~s}^{-1}$ photosynthetic photon flux density. The experiments were established in a completely randomized design. ANOVA and Duncan's multiple range test (DMRT) were used for comparison among the treatment means.

\section{Acclimatization}

Six-month-old-vitro-grown complete plantlets were rinsed under running water to remove agar, soaked in $0.2 \%$ Bavistin for $1 \mathrm{~h}$, transferred to 1.5 inch plastic pots containing sterilized coconut peat and tree fern (1:1), and placed in trays. Those plantlets were grown in the greenhouse under $60 \%$ shading and control relative humidity at $80 \%$. One hundred plantlets were used for 5 replications, 20 plantlets per replication. After 1 month of acclimatization, the percentage of survival plantlets was recorded.

\section{RESULTS AND DISCUSSION}

\section{Seed morphology and viability}

The seed viability test, as stained by TTC, showed the presence of non-staining small embryos in their seeds (Fig. 1a) and red staining (Fig. 1b). The viability was recorded to be $99.02 \%$. Those embryos could germinate in an appropriate culture medium and environment. In addition, embryos or seeds could germinate because they were completely developed ${ }^{14}$.

\section{Effects of basal media on seed germination}

The orchid seeds cultured on 1/2 B5 medium supplemented with $0.1 \%$ AC for 30 days gave the highest germination percentage at $97 \%$; whereas, $1 / 2 \mathrm{MS}$ medium and ND medium gave only $76 \%$ and $67 \%$, respectively (Table 1, Fig. 2). During sowing seeds in this culture medium, seed germination occurred after the imbibition, which resulted in swelling of the 

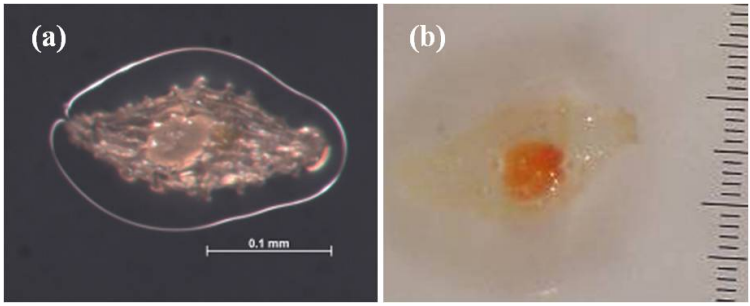

Fig. 1 Viable seeds of G. speciosum evaluated by TTC staining; (a) a non-red stained embryo; (b) a red stained embryo.

Table 1 Percentage of seed germination after 30 days of culture.

\begin{tabular}{lc}
\hline Medium & Germination $(\%)$ \\
\hline $1 / 2$ B5 & $96.9^{\mathrm{a}}$ \\
$1 / 2$ MS & $76.5^{\mathrm{b}}$ \\
ND & $66.7^{\mathrm{c}}$ \\
F-test & $p \leqslant 0.01$ \\
C.V. $(\%)$ & 4.3 \\
\hline
\end{tabular}

Means followed by different letters within a column are significantly different by DMRT.

embryos, and then the seed coats were ruptured by the emerging of germinated embryos, so the embryo enlargement and the papillae appeared on the one end of protocorms (Fig. 2a). Since seed viability was high, the effects of $1 / 2$ MS and ND media on lower seed germination were confirmed. Hence $1 / 2$ B5 medium is recommended for asymbiotic germination of G. speciosum. Moreover, asymbiotic germination technique is much easier than symbiotic germination.

Asymbiotic seed germination of orchid seeds is an efficient propagation method for large-scale production of orchid plants. However, $1 / 2$ B5 and ND media have never been applied to promote seed germination in G. speciosum before. An in-depth review on in vitro orchid seed germination was reported by Kauth et al ${ }^{15}$. Many protocols for in vitro seed germination, in orchids have been described ${ }^{14,16}$. In those reports, seed germination and development were significantly influenced by capsule maturity and pretreatment of seeds, medium compositions, culture conditions, culture methods, as well as other conditions. Some experimental results, such as the germination percentage of seeds of the same species on the same medium, were inconsistent or even contradictory ${ }^{16}$.

For propagation of $G$. speciosum in vitro, Sopalun et $\mathrm{al}^{13}$ reported the induction of PLBs from shoot tips in $1 / 2$ MS liquid medium without any plant regulators (PGRs). This study showed that the seeds germinated
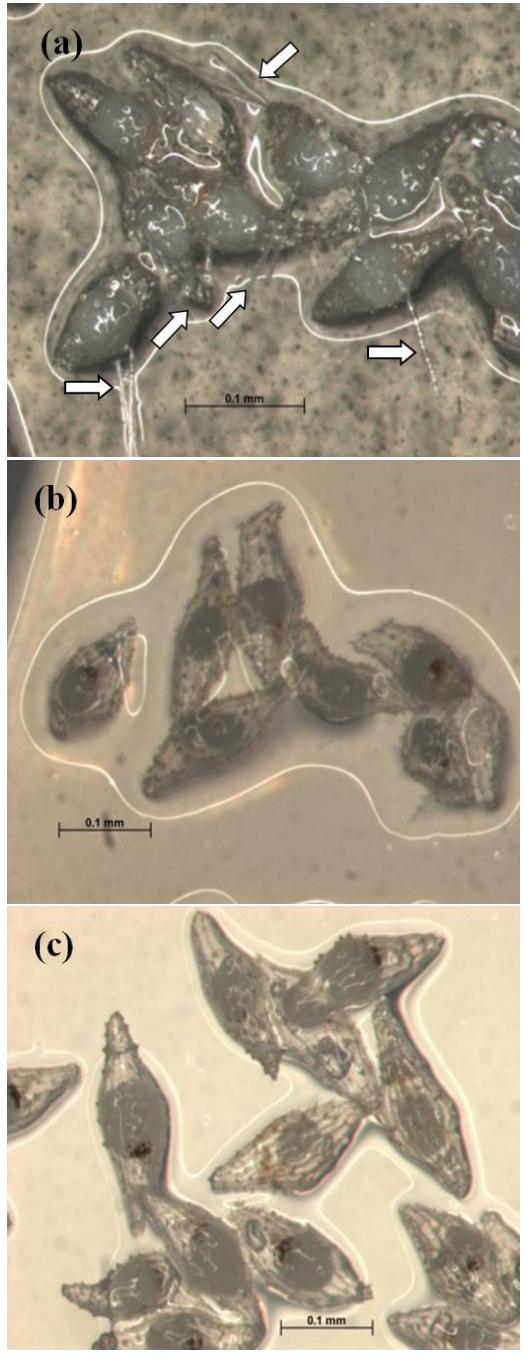

Fig. 2 Germination of $G$. speciosum seeds after 30 days of culture: (a) on $1 / 2$ B5 medium which showed the enlargement of embryos and papillae (arrow), (b) on ND medium, and (c) on $1 / 2$ MS medium.

well on $1 / 2$ B5 solidified medium but the seeds cultured on $1 / 2$ MS medium resulted in a larger protocorm enlargement after 3 months of culture. Similar results were obtained by Abbas et al ${ }^{17}$ who reported successful propagation of $G$. scriptum by seed germination in vitro. The best medium for germination of G. scriptum was Knudson C medium supplemented with $30 \% \mathrm{CW}$ and the best medium for seedling development was $1 / 2$ MS medium supplemented with $40 \% \mathrm{CW}$. Moreover, Zhang et al ${ }^{18}$ reported that full strength of MS medium contains high ionic concentration of nutrient salts; therefore, $1 / 2 \mathrm{MS}$ could adequately support rapid production of protocorms in orchids. Thus the $1 / 2 \mathrm{MS}$ medium was suitable for PLB induction in this study. 

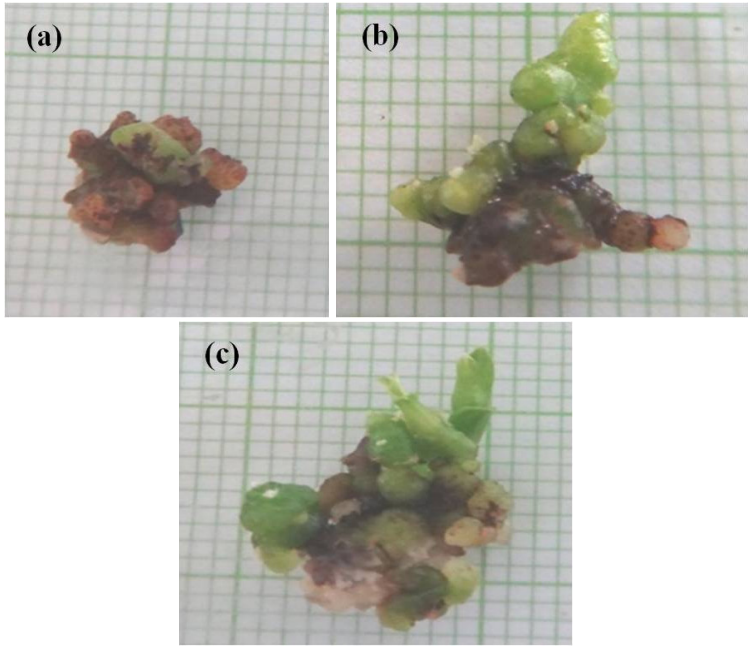

Fig. 3 Development of new PLBs from culturing a protocorm (a) on $1 / 2$ MS medium without PGRs, (b) on $1 / 2$ MS medium containing $1 \mathrm{mg} / \mathrm{l} \mathrm{BA}$ and $0.5 \mathrm{mg} / \mathrm{l} \mathrm{NAA}$ without $\mathrm{AC}$, and (c) with $0.2 \% \mathrm{AC}$.

Table 2 Effects of PGRs and AC on PLB formation and proliferation after 10 weeks of culture.

\begin{tabular}{lcccc}
\hline Medium & $\begin{array}{c}\text { AC } \\
(\%)\end{array}$ & $\begin{array}{c}\text { PLB for- } \\
\text { mation (\%) }\end{array}$ & $\begin{array}{c}\text { No. of PLBs } \\
\text { per explant }\end{array}$ & $\begin{array}{c}\text { PLB prolif- } \\
\text { eration }(\%)\end{array}$ \\
\hline PGR-free $1 / 2$ MS & 0.0 & $21.7^{\mathrm{b}}$ & $2.91^{\mathrm{d}}$ & $6.7^{\mathrm{c}}$ \\
& 0.2 & $28.3^{\mathrm{b}}$ & $4.63^{\mathrm{c}}$ & $21.7^{\mathrm{b}}$ \\
1/2 MS+BA+ NAA & 0.0 & $46.7^{\mathrm{a}}$ & $5.84^{\mathrm{b}}$ & $11.7^{\mathrm{bc}}$ \\
& 0.2 & $63.3^{\mathrm{a}}$ & $6.87^{\mathrm{a}}$ & $46.7^{\mathrm{a}}$ \\
F-test & & $p \leqslant 0.01$ & $p \leqslant 0.01$ & $p \leqslant 0.01$ \\
C.V. $(\%)$ & & 36.4 & 12.0 & 39.1 \\
\hline
\end{tabular}

Means followed by different letters within a column are significantly different by DMRT.

\section{PLB induction, proliferation, and plant regeneration}

The highest percentage of PLB formation (63\%) was obtained on $1 / 2$ MS medium supplemented with $1 \mathrm{mg} / \mathrm{l}$ BA in combination with $0.5 \mathrm{mg} / 1 \mathrm{NAA}, 15 \% \mathrm{CW}$, $0.2 \% \mathrm{AC}$ and $0.7 \%$ agar. Statistically significant difference was observed among treatments. Culture media supplemented with AC seemed to induce PLB proliferation better than culture medium without AC (Fig. 3). AC adsorbed the inhibitory phenolic and carboxylic compounds produced by the tissues in culture $^{19}$, so the medium without AC showed browning of PLBs (Fig. 3b) as a result of low proliferation rate of PLBs (Table 2). Half-strength MS medium without PGRs was suitable for plantlet regeneration which gave the number of shoots $(>3 \mathrm{~cm}$ long) at 6.67 shoots. The medium supplemented with BA promoted the PLB proliferation resulted in an inferior growth

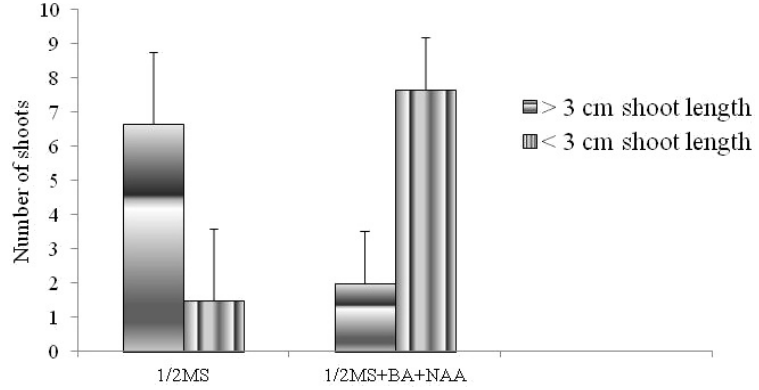

Fig. 4 Shoot development from PLBs cultured on $1 / 2$ MS medium without PGRs and $1 / 2$ MS containing $1 \mathrm{mg} / \mathrm{l} \mathrm{BA}$, $0.5 \mathrm{mg} / \mathrm{l} \mathrm{NAA}$ and $0.2 \%$ AC after 3 months of culture.

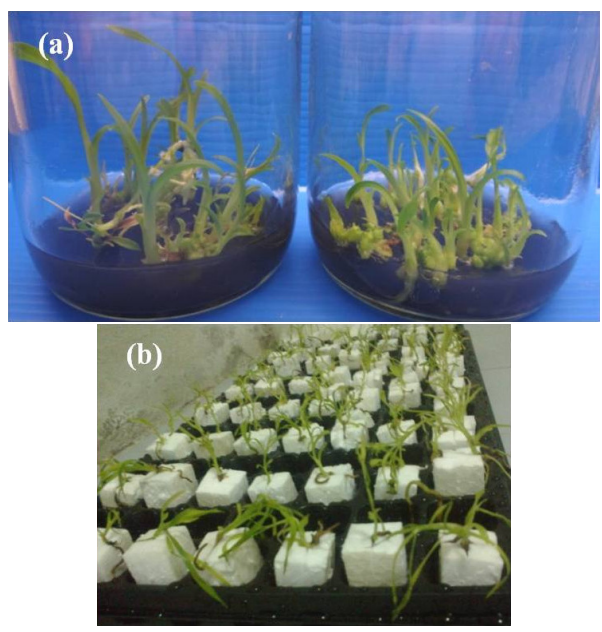

Fig. 5 (a) Shoot development from PLBs cultured on $1 / 2$ MS medium without PGRs (left) and $1 / 2$ MS containing $1 \mathrm{mg} / 1$ BA, $0.5 \mathrm{mg} / 1 \mathrm{NAA}$, and $0.2 \% \mathrm{AC}$ (right) after 3 months of culture and (b) survival of plantlets after 1 month of acclimatization.

of plantlets (Fig. 4). Similar results were obtained by Abbas et al ${ }^{17}$ who found that the best culture medium suitable for seedling development of G. scriptum was $1 / 2$ MS medium supplemented with $15 \% \mathrm{CW}$. The PLBs can be regenerated into complete plantlets with vigorous shoot and root formation after 3 months of culture (Fig. 5a).

\section{Greenhouse acclimatization}

After 6 months of culture on $1 / 2$ MS medium without PGRs and supplemented with $2 \%$ sucrose and $0.2 \%$ AC, complete plantlets were formed. Fully developed plantlets with vigorous shoots and roots were successfully acclimatized and grown under the greenhouse with about $60 \%$ shading and $80 \%$ relative humidity. A total of 100 plantlets were planted. After 1 month 
(Fig. 5b), the numbers of survival were 84 plantlets. The survival rate of plantlets was $70 \%$.

Acknowledgements: This study was supported by the Biology Program, Faculty of Science and Technology, Suratthani Rajabhat University, Suratthani, and the Department of Plant Science, Faculty of Natural Resources, Prince of Songkla University, Hat Yai, Songkhla. The authors wish to thank Dr Tim Marks and Mr Phil Seaton, Seed Conservation Department, Royal Botanic Gardens, Kew, Wakehurst Place, UK for their kind assistance on training in conservation of orchid seeds.

\section{REFERENCES}

1. Nagaraju V, Mani SK (2005) Rapid in vitro propagation of orchid Zygopetalum intermedium. J Plant Biochem Biotechnol 14, 27-32.

2. Chugh S, Guha S, Rao IU (2009) Micropropagation of orchids: a review on the potential of different explants. Sci Hort 122, 507-20.

3. Yam TW, Chua J, Tay F, Ang P (2010) Conservation of the native orchids through seedling culture and reintroduction-A Singapore experience. Bot Rev 76, 263-74.

4. Morel GM (1960) Producing virus-free Cymbidium. Am Orchid Soc Bull 29, 495-7.

5. Ket NV, Hahn EJ, Park S, Chakrabarty D, Paek KY (2004) Micropropagation of an endangered orchid Anoectochilus formosanus. J Plant Biol 48, 339-44.

6. Roy J, Banerjee N (2003) Induction of callus and plant regeneration from shoot tip explants of Dendrobium fimbriatum Lindl. var. oculatum Hk. f. Sci Hort 97, $333-40$.

7. Teixeira da Silva JA, Singh N, Tanaka M (2006) Priming biotic factors for optimal protocorm-like body and callus induction in hybrid Cymbidium (Orchidaceae), and assessment of cytogenetic stability in regenerated plantlets. Plant Cell Tissue Organ Cult 84, 135-44.

8. Vacin E, Went F (1949) Some pH changes in nutrient solutions. Bot Gaz 110, 605-13.

9. Murashige T, Skoog F (1962) A revised medium for rapid growth and bioassays with tobacco tissue culture. Physiol Plant 15, 473-97.

10. Lakshmanan P, Loh CS, Goh CJ (1995) An in vitro method for rapid regeneration of a monopodial orchid hybrid Aranda Deborah using thin section culture. Plant Cell Rep 14, 510-4.

11. Ravindra M, Gangadhar M, Natarajan K (2004) Efficient regeneration of Vanda coerulea, an endangered orchid using thidiazuron. Plant Cell Tissue Organ Cult 76, 289-93.

12. Chen J, Chang W (2000) Efficient plant regeneration through somatic embryogenesis from callus culture of Oncidium (Orchidaceae). Plant Sci 160, 87-93.

13. Sopalun K, Thammasiri K, Ishikawa K (2010) Micropropagation of the Thai orchid Grammatophyllum speciosum Blume. Plant Cell Tissue Organ Cult 101, 143-50.

14. Zeng S, Wang J, Wu K, Teixeira da Silva JA, Singh N, Zhang J, Duan J (2013) In vitro propagation of Paphiopedilum hangianum Perner \& Gruss. Sci Hort 151, 147-56.

15. Kauth PJ, Kane ME, Vendrame WA, Adams CR (2008) Asymbiotic germination response to photoperiod and nutritional media in six populations of Calopogon tuberosus var. tuberosus (Orchidaceae): Evidence for ecotypic differentiation. Ann Bot 102, 783-93.

16. Chen JT, Chang WC (2004) Induction of repetitive embryogenesis from seed-derived protocorms of Phalaenopsis amabilis var. formosa Shimadzu. In Vitro Cell Dev Biol Plant 40, 290-3.

17. Abbas B, Listyorini FH, Amriati B (2011) In vitro seed germination and plantlets development of Grammatophyllum scriptum Lindl. (Orchidaceae). Int Res J Plant Sci 2, 154-9.

18. Zhang ZG, Wang L, Liu H, Cai ZG, Han XZ, Zhao LH, Luo ZJ (1993) Studies on culture medium for protocorm differentiation in Dendrobium candidum Wall. ex. Lindl. China J Chin Materia Med 18, 16-9 (in Chinese).

19. Swarna Piria R, Rajmohan K, Suresh S (2008) In vitro production of protocorms and protocorm like bodies in orchids-A review. Agr Rev 29, 40-7. 